\title{
colonização privada e oficial no primeiro governo vargas: integração do mercado e desenvolvimento econômico*
} private and official colonization in first vargas
government: market integration and economic
development

Julio Cesar Zorzenon Costa $\star \star$

Universidade Federal de São Paulo, Campus Osasco, Osasco, São Paulo, Brasil

RESUMO

O trabalho relaciona o avanço das fronteiras econômicas e a política colonizadora do primeiro governo Vargas (1930-1945) com a integração do mercado interno brasileiro. Ao inserir novas áreas nos circuitos econômicos, vinculando-as aos centros dinâmicos da economia, e ao procurar garantir a manutenção da integridade territorial do país, o avanço da fronteira, por meio da colonização, visava à construção de um mercado potencial de grandes proporções e, com isso, o desenvolvimento de um padrão de acumulação nucleado pela industrialização. No período em questão, é possível perceber a existência de uma nítida "divisão do trabalho colonizador" entre iniciativas privadas e oficiais. A colonização do norte paranaense é um exemplo de iniciativa privada de colonização, ao passo que a experiência oficial vincula-se à colonização do sudoeste paulista, do Vale do Ribeira, e aos programas de integração de partes de Goiás e Mato Grosso.

Palavras-chave: Política colonizadora. Primeiro governo Vargas. Colonização privada. Colonização oficial.

\section{Abstract}

The work relates the advancement of economic and the colonizer frontiers policy of the first Vargas government (1930-1945) with the integration of the Brazilian market. When entering new areas in economic circuits, linking them to the dynamics centers of the economy, and seeking to ensure the maintenance of the territorial integrity of the country, the advancing frontier, through colonization, aimed at building a potential market of large proportions and thereby developing a pattern of accumulation nucleated by industrialization. In the period in question, it is possible to perceive the existence of a clear "division of colonizer labor" between private and public initiatives. The colonization of north of Paraná is an example of private colonization, while the official experience is linked to the colonization of the southwest of São Paulo, the Vale do Ribeira, and to integration programs of parts of Goiás and Mato Grosso.

Keywords: Colonization policy. FirstVargas government. Private colonization. Public colonization.

\footnotetext{
* Submetido: 12 de julho de 2013; aceito: 27 de setembro de 2013.

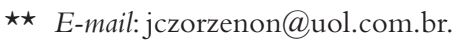




\section{Introdução}

O avanço das fronteiras econômicas, a partir dos anos 1930, teve por objetivos a expansão e a integração do mercado interno brasileiro. Isso distingue, indubitavelmente, esse processo em relação às experiências anteriores ocorridas no Brasil. As constantes afirmações de Vargas, ressaltando a necessidade de superação do "arquipélago econômico" brasileiro, constituem-se como uma de suas mais importantes evidências.

Alguns comparam o nosso país a uma ilha ou a um arquipélago. Há regiões ricas, intensamente povoadas e industrializadas, e há regiões pobres, onde falta densidade demográfica e onde a escassez de população e de transportes ainda não proporciona os meios necessários à formação de suas riquezas. Não que essas zonas sejam áridas: é que a civilização ainda não chegou até lá, com a intensidade dos seus meios de produção. De modo que o sentido legítimo de nosso imperialismo é crescer dentro de nós mesmos e levar as nossas fronteiras econômicas até ao limite das fronteiras políticas, fazendo com que todo o Brasil prospere harmonicamente. (Vargas, 1943a, p. 131-132)

A melhor situação econômica não coincide, como é sabido, com os núcleos de maior densidade demográfica, demonstrando isso, portanto, que há defeitos do sistema produtivo a corrigir. $\mathrm{O}$ deslocamento da mão de obra é feito sem método, por processos francamente rotineiros e, mesmo, nocivos. O governo irá sem perda de tempo, visto já estar em funcionamento e trabalhando com eficiência o Conselho de Imigração e Colonização, promover os meios de regular o assunto em relação às populações nacionais, criando o povoamento e organizar a exploração racional de faixas do Centro e do Oeste e estabelecendo núcleos novos de expansão das nossas energias produtoras. [...] É, aliás, no sentido de promover a colonização interior que o Governo dirige, atualmente, as suas vistas, com o intuito de fixar em zonas mais produtivas e menos propícias a flagelos os excedentes de população de certas regiões do país. (Vargas, 1943a, p. 282-283, 299)

A conquista do interior, vinculada à expansão e à integração do mercado brasileiro, amplificou a importância da política colonizadora. Isso aproximou os objetivos colonizadores das ideias defendidas pelo pensamento modernista e pelo setor mais radical do tenentismo. O modernismo, em suas diferentes tendências, defendia, já na década de 1920, a intervenção do Estado nos locais onde não parecia ser possível 
um impulso modernizador próprio (Lahuerta, 1997, p. 100-101). Após o movimento de 1930, o Clube 3 de Outubro, que aglutinava a ala mais radical do tenentismo, passou a reivindicar a instalação de núcleos de colonização, principalmente nas áreas mais atrasadas economicamente (Camargo, 1981, p. 134). Uma observação atenta das propostas de colonização oficial, construídas no período do primeiro governo Vargas, evidencia a aceitação dos princípios acima indicados.

No período que nos ocupa, houve, assim, uma reorientação do papel da colonização nos processos de avanço da fronteira econômica. Essa nova orientação se expressou por meio de uma espécie de "divisão do trabalho colonizador". As áreas que pudessem ser inseridas de maneira “espontânea" nos circuitos econômicos, seguindo dinâmica própria do capital privado, e que conseguissem atrair um contingente de trabalhadores e/ou pequenos proprietários já "disciplinados" para uma produção agrícola de excedentes, poderiam, e deveriam, ser objetos da colonização privada. As áreas consideradas adormecidas e não interessantes à inversão privada de capitais, e para as quais seriam dirigidos trabalhadores ainda não totalmente disciplinados para uma produção para o mercado, deveriam ficar a cargo de programas oficiais de colonização. Por isso, a colonização oficial foi, durante o período, sendo construída paulatinamente, como resultado de propostas e ações planificadas. Esse processo atingiu o seu auge com a criação das Colônias Agrícolas Nacionais (CANs), em 1943.

Apesar de as propostas de colonização terem se voltado ao desenvolvimento de atividades agrícolas, elas não se distanciavam dos objetivos de integração do mercado interno e do desenvolvimento de um novo padrão de acumulação, nucleado pela industrialização. Isso porque a agricultura estava começando a deixar de ser a principal variável na formação da renda interna e começava a assumir novos e importantes papéis: a oferta de matéria-prima às indústrias e o atendimento das necessidades básicas das populações urbanas, que cresciam rapidamente. Acreditava-se, ao mesmo tempo, que a colonização, baseada na pequena propriedade, imporia aos colonos a necessidade de se tornarem consumidores de mercadorias industriais.

A colonização com base na pequena produção agrícola vinculava-se, assim, às políticas de desenvolvimento industrial. A industrialização brasileira necessitava da ampliação do mercado interno. Era necessário 
integrar aos circuitos econômicos as regiões consideradas não produtoras e não consumidoras de mercadorias.

A colonização, ao encaminhar a conquista interna, subordinando novas áreas aos centros dinâmicos da atividade econômica, tornou-se fundamental para a integração econômica, para a manutenção da integridade territorial do país e, dessa maneira, para a formação de um mercado potencial de grandes proporções:

Como superar a vulnerabilidade da economia brasileira calcada em exportações de produtos primários e em economias regionais estanques, que punham em questão a viabilidade e a unidade do país? A política de desenvolvimento acelerado, além de galvanizar apoio de setores fundamentais, parecia ser a resposta mais eficaz ao problema da fragmentação do país em economias regionais pouco integradas. Embora o programa de Vargas não contivesse medidas efetivas visando um desenvolvimento mais equilibrado entre regiões do país e a redistribuição da renda, o discurso e as medidas implementadas no sentido de criar um verdadeiro mercado nacional sugerem que o programa de crescimento acelerado, consistia em um verdadeiro projeto de consolidação da nação a partir da hegemonia do capitalismo industrial. (Corsi, 2002, p. 6)

A expansão territorial, necessária ao desenvolvimento capitalista, poderia realizar-se internamente no Brasil, devido à existência de abundantes fundos territoriais ${ }^{1}$. Isso se ligava à ideia de superação, por meio do "nosso imperialismo interno" (Vargas, 1943a, p. 285), do “arquipélago econômico" brasileiro, que resultou das práticas econômicas do regime vigente no pré-1930.

A existência de uma divisão do trabalho colonizador, a que nos referimos anteriormente, deveu-se ao fato de que, no período, conviveram simultaneamente experiências e propostas colonizadoras de caráter privado e oficial, que apresentaram grande visibilidade. No primeiro caso, o exemplo mais significativo é o da colonização do norte paranaense. $\mathrm{O}$ segundo caso pode ser verificado, ao lado das práticas de

\footnotetext{
1 A expansão territorial era, no período que nos ocupa, uma preocupação presente em diferentes economias capitalistas, que visavam acelerar o crescimento e o desenvolvimento econômico. Era o caso das ações imperialistas por parte da Alemanha e Itália, por exemplo. No Brasil, tal concepção foi reinterpretada como conquista interna de nossos fundos territoriais.
} 
colonização desenvolvidas no sudoeste paulista e noVale do Ribeira, no programa Marcha para o Oeste, que visava integrar, principalmente, os estados de Goiás e Mato Grosso à atividade econômica.

\section{A divisão do trabalho colonizador: a colonização privada}

A colonização efetuada no norte do Paraná pela Companhia de Terras do Norte do Paraná (CTNP) foi o mais destacado exemplo de colonização privada, baseada em pequenas e médias propriedades, do período: "No norte do Paraná podem ser observadas fazendas que se aproximam dos 1.000 alqueires ou mesmo os ultrapassam. Mas aqui elas têm nas vizinhanças, milhares de pequenas propriedades com uma dezena de alqueires, uma trintena no máximo" (Monbeig, 1994, p. 214).

Foi responsável pela inserção de uma área, até então, pouco tocada pela atividade econômica. A ocupação, que se deu sob a forma de colonização dirigida, envolveu uma área superior a 500.000 alqueires paulistas e teve como centro irradiador o município de Londrina.

Nessa área foi estabelecido um complexo colonizador, com a construção de aproximadamente $4.000 \mathrm{~km}$ de estradas de rodagem e a aquisição de uma estrada de ferro que atingiu Londrina em 1935 e Apucarana em 1937 (Monbeig, 1994, p. 207). Envolveu, também, a construção de usinas hidrelétricas e de cimento (que se localizava no estado de São Paulo, mais precisamente em Itapeva), indústrias de cerâmica e fazendas de engorda de gado².

A organização das propriedades, tanto no que diz respeito à sua localização e à sua aquisição pelos colonos quanto ao sistema produtivo, que envolvia a constituição de redes de produção, distribuição, circulação e consumo, demonstra a existência de uma planificação do processo de ocupação demográfica e produtiva da região.

A venda dos lotes foi financiada. Para garantir o pagamento das prestações, o colono recebia orientação e acompanhamento técnico durante as primeiras plantações. Os lotes eram interligados por meio de

2 Para tal, ver Augusto, 1977, p. 36-40; e Jarreta, 1984, p. 83-93. 
estradas de rodagem que também procuravam ligá-los aos patrimônios ${ }^{3}$ $\mathrm{e} /$ ou às cidades menores, que não distavam mais do que $18 \mathrm{~km}$ uns dos outros. Os patrimônios e as cidades menores interligavam-se a centros urbanos maiores, que foram planejados como polos regionais, e estavam situados a uma distância aproximada de $100 \mathrm{~km}$. Tais polos teriam fácil acesso ao transporte ferroviário e seriam servidos de estradas que os ligariam diretamente ao estado de São Paulo e, daí, com a capital paulista (Almeida, 1997, p. 94).

Graças a essa rede, que era excepcional não só pela densidade, mas também pela quantidade, não existe um lote sequer que não tenha articulação por um bom caminho e não há um só colono muito afastado de um centro comercial. [...] O sistema rodoviário do Norte do Paraná foi concebido de maneira a facilitar as relações entre os sítios e as cidades e do campo com as casas de comércio e as estações ferroviárias. Sua amplitude e sua qualidade são um bom exemplo de ação dos loteadores para proteger o pioneiro contra o isolamento e para amparar a economia totalmente orientada para o comércio. (Monbeig, 1994, p. 232)

O tamanho das propriedades variava de acordo com a proximidade dos patrimônios ou das cidades. As mais próximas, voltadas a atender o mercado local, tinham uma área de aproximadamente 3 alqueires. As mais distantes, que produziam para o mercado paulista ou para a exportação, embora pudessem variar de tamanho, tinham, em média, 20 alqueires (Almeida, 1997, p. 95).

A opção pela pequena propriedade era normalmente explicada pelo fato de que esse seria o melhor meio de se garantir o rápido povoamento e o suprimento de força de trabalho, uma vez que se acreditava que as condições econômicas do período, marcadas pela forte crise econômica, impediam que os objetivos acima fossem alcançados pelo regime de grandes propriedades. Também, pelo interesse de se estabelecer uma atividade econômica regional com alto grau de dinamismo próprio, que

3 Segundo Almeida, os patrimônios "são pequenos núcleos populacionais planejados e implantados pela CTNP, onde se localizavam a igreja, a escola, o salão de festas, o campo de futebol, o campo de bocha, a escola, a venda e a máquina de beneficiamento de cereais. Circundados pelos sítios, além de constituírem espaços para as atividades lúdico-religiosas dos habitantes rurais, cumpriam a função de intermediar as relações sócio-econômicas entre campo e cidade" (Almeida, 1997, p. 43). 
possibilitasse o consumo de mercadorias e serviços oferecidos por empresas criadas pela própria companhia colonizadora, como é o caso das já citadas companhias: a usina hidrelétrica e a fábrica de cimento. Mas é importante destacarmos o que afirma Augusto:

Também, a companhia agia como intermediária, adquirindo a preços compensadores a produção cafeeira das diversas propriedades; nesse sentido, a impossibilidade de pequenos proprietários dispersos se colocarem no mercado do produto em condições de defender seus interesses conduzia a que tivesse condições (a Cia.) de auferir lucros também dessa forma. Fica claro, então, que a colonização é levada a efeito "como empreendimento econômico: empresas imobiliárias, ferroviárias, comerciais, bancárias etc., loteiam terras, transportam mercadorias, compram e vendem, financiam a produção e o comércio [...]"4. Surge, assim, como resultado direto da necessidade de reprodução da sociedade capitalista. (Augusto, 1977, p. 38-39)

Assim, o processo de Colonização do Norte do Paraná, nas décadas de 1930 e 1940, representou a incorporação da região pelo capitalismo brasileiro no estágio de desenvolvimento que este começava a assumir naquele momento, em que a agricultura estava passando a se subordinar à industrialização.

Aparentemente, a experiência da colonização privada do norte do Paraná parecia seguir o encaminhamento "tradicional" do capital agrário e comercial. Esse encaminhamento, no entanto, encontrava-se muito mais relacionado às exigências do novo padrão de acumulação, nucleado pela industrialização, que se desenvolvia no pós-1930 e que passava a subordinar aqueles mesmos capitais a uma nova lógica econômica. Para lá se dirigiram as frentes pioneiras paulistas baseadas no café. E, nesse momento, a agricultura de exportação estava começando a deixar de ser o fator primordial do dinamismo econômico brasileiro, embora mantivesse o caráter instrumental de alcançar divisas para a importação de equipamentos industriais.

O café alcançou o Paraná num momento em que já não se encontrava nele a base da acumulação capitalista no Brasil; entretanto, persistia na cafeicultura uma fonte de recursos essencial para a capitalização de um outro

$4 \quad$ A passagem citada é de Martins, 1971. 
setor - o industrial - que havia assumido a dominância. [...] No momento em que se intensifica no estado (do Paraná) a cafeicultura, ao setor exportador - apoiado no café - ainda cabia importante função no sentido de propiciar divisas para a industrialização que se expandia. (Augusto, 1977, p. 39)

A opção pelo café se explica pelo fato, já aduzido anteriormente, de que a comercialização do café, por meio de pequenos proprietários, levava necessariamente à intermediação da companhia colonizadora, que comprava a produção a preços compensadores em regime de monopsônio e poderia revendê-la a preços mais compensadores ainda, catalisando, assim, a acumulação de capital mediante o controle dos mecanismos de fixação de preços. Por outro lado, na década de 1930 apresentava, ainda, outra grande vantagem, que era a não restrição à produção cafeeira que vigorava sobre São Paulo (Augusto, 1977, p. 34). Afora o seu caráter altamente ufanista, a citação que segue ilustra bem o caso:

Na verdade, a afluência de imigrantes para o Paraná nesse período de quarenta anos representou a mais importante experiência de migração e colonização bem sucedida neste século no Brasil. Mais uma vez, teve basicamente o caráter de um movimento do campo para o campo, animando-o a finalidade de desenvolver a lucrativa cultura do café nas terras férteis das zonas norte e oeste do Paraná. [...] é interessante notar que o sistema de posse da terra nas regiões norte e oeste do Paraná resultou em numerosas propriedades pequenas e médias, nas quais famílias independentes de agricultores deram sadia base social ao meio rural. [...] O Paraná foi essencialmente colonizado por paulistas, com participação insignificante de imigrantes de outros Estados. Com isto, o Estado beneficiou-se muito ao receber uma estirpe promissora de capital humano do Estado mais avançado do país. Alem disso, os mais bem treinados paulistas não foram tanto empurrados do meio onde viviam como atraídos para empreendimentos mais lucrativos no Paraná, contribuindo, no processo, com apreciável espírito empresarial e um volume razoável de capital físico. (Graham, 1971, p. 23-25)

Era, portanto, uma nova área a serviço da inversão privada de capitais. Aí o processo de integração econômica pôde se dar de forma "espontânea" com pouca necessidade de intervenção estatal, já que o capital, pela sua própria dinâmica, para lá se dirigia: 
Pouco financiamento público direto e planejamento foram necessários desde que a lucratividade de uma cultura comercial de exportação como o café era suficiente alta para que forças e organizações privadas de mercado pudessem estimular, financiar e dirigir este grande movimento migratório. (Graham, 1971, p. 23)

A região, ao ser conectada de forma mais consistente aos circuitos econômicos, pôde, ainda, responder a outras exigências do novo padrão de acumulação, como a de se tornar uma região consumidora de mercadorias e a de produzir alimentos e matérias-primas a baixo custo, colaborando para reduzir, dessa maneira, os custos da produção industrial, ao rebaixar os montantes necessários à cobertura do capital constante e do capital variável das indústrias, principalmente das que se desenvolviam em São Paulo (capital e estado)

A facilidade de comunicação, tanto com o mercado local como o interestadual, e a relativa proximidade com o centro dinâmico da economia nacional, de onde partiam os influxos de integração econômica, explicam o rápido desenvolvimento econômico e populacional da região a partir da experiência da colonização, de tal sorte que a população triplicou nas três primeiras décadas, atingindo 48,6\% da população paranaense em 1960 (Almeida, 1997, p. 22), e a sua produção cafeeira atingiu a cifra de $48 \%$ da produção brasileira no mesmo período (Augusto, 1977, p. 40).

Não se deve entender, contudo, que as razões para esse explosivo processo de transformação capitalista e de crescimento econômico, bem como o aparente sucesso na atividade colonizadora, reside no simples fato de que essa experiência originou-se de uma iniciativa privada. Essas razões se encontram, sobretudo, no fato de que a iniciativa privada pôde incorporar um processo que já se encontrava em curso pela própria dinâmica do desenvolvimento capitalista. Não se tratou de um empreendimento privado com objetivo de introduzir a região nos processos de desenvolvimento, mas o seu contrário, o de capturar para o capital uma oportunidade de inversão em atividades imobiliárias, agrícolas e comerciais de uma região que se tornava atraente para o investimento privado e que seguia os influxos da economia dominante no período, a paulista. Era uma área que se anexava ao processo de expansão paulista que, naquele momento, já se encontrava marcado pelo de- 
senvolvimento industrial. Foi incorporada como área subordinada, mas integrante do desenvolvimento econômico que se processava de maneira centralizada em São Paulo.

A justificativa oficial para a venda de terras do norte do Paraná à CTNP foi o objetivo de se evitar a posse ilegal das terras. Entretanto, a CTNP não encontrou a terra tão vazia como se afirmava, ela era, embora pouco densamente, ocupada anteriormente por posseiros, safristas e por populações indígenas, que impuseram alguns problemas que tiveram que ser resolvidos para não impedirem a atividade colonizadora.

Não tardou também que se tivesse vez na região o surgimento de mecanismos de exploração do pequeno proprietário pela CNTP, como afirma Almeida:

Os migrantes, ao se tornarem, no Norte do Paraná, pequenos proprietários não capitalizados, produtores de mercadorias e de seus meios de subsistência, vivenciaram uma situação inovadora e contraditória determinada pelo modo específico pelo qual se integraram às atividades agrícolas da região. Apesar de se transformarem em proprietários de terra e assumirem a condição de trabalhadores independentes, conviviam com a possibilidade de proletarização virtual, caso não conseguissem pagar as terras para a CNTP, enfrentar as oscilações do mercado e as possíveis crises da cafeicultura. Consequentemente, na prática, foram obrigados a incorporar a maioria dos membros da família na produção e em funções assalariadas, utilizando o sobretrabalho, cujos resultados revertiam em dinheiro para o pagamento das terras. (Almeida, 1997, p. 25-26)

O pequeno proprietário, premido pela necessidade de pagamento das prestações do lote, com dificuldades de colocar a sua produção no mercado, teve que aceitar a venda de sua produção a preços condicionados pela companhia e, devido a isso, incorporar toda a família na atividade produtiva de sua propriedade, aumentar a jornada de trabalho familiar e empregar alguns membros da família em trabalho assalariado em outras atividades, possibilitando, dessa forma, a geração de um sobretrabalho apto a ser apropriado, em forma de pagamento das prestações do lote, pela companhia colonizadora. Como podemos perceber, o pequeno proprietário esteve submetido a mecanismos de apropriação do excedente, que reproduziram as formas clássicas de acumulação de capital, nas áreas de avanço da fronteira econômica. 
A colonização do norte do Paraná esteve, desde o seu início, ligada ao dinamismo da economia paulista. A integração da região se deu de forma muito mais estreita com São Paulo do que com qualquer parte do território nacional, inclusive o próprio Paraná. O sistema de transporte procurava ligá-la com São Paulo, onde uma parte considerável de sua produção seria exportada ou consumida. De São Paulo chegavam os principais produtos manufaturados e insumos industriais, assim como o principal contingente migratório.

A forte ligação do norte do Paraná com a economia paulista seria posteriormente confirmada pelas próprias autoridades paranaenses, na década de 1960, com a criação da CODEPAR (Companhia de Desenvolvimento Econômico do Paraná). Nessa instituição que procurou desenvolver políticas estaduais para o desenvolvimento do Paraná, com a unificação econômica das regiões que compunham o estado, as autoridades políticas e econômicas sempre aludiam ao fato de que a maior parte do excedente econômico norte-paranaense era desviado e apropriado pela economia e pelos grupos empresariais paulistas. Tratava-se, segundo essas autoridades, de mudar o sentido dessa integração econômica, fazendo com que a economia do norte do estado viesse a "beneficiar” a economia paranaense (Augusto, 1977, p. 42). Nessa avaliação, o norte do Paraná era entendido como uma região periférica ao desenvolvimento econômico paulista.

Mas, nesse aspecto, é importante reafirmar, de acordo com Augusto, que, para além de uma incorporação periférica, puramente espacial, a economia norte-paranaense subordinou-se, por meio de sua atividade agrícola e de seus pequenos proprietários, ao processo de acumulação industrial, que, no período que nos ocupa, tinha São Paulo como seu centro dinâmico.

É necessário reconhecer que a expansão econômica não se restringe aos limites administrativos estaduais. Esse é mais um elemento que reafirma que naquele momento todos os esforços encontravam-se canalizados para a construção de um espaço econômico nacional, com a integração do mercado interno, inclusive do mercado de trabalho. A centralização política conduzida pelo Estado, no primeiro governo Vargas, que se ampliou durante o Estado Novo, quando a autonomia dos estados foi fortemente reduzida, serviu, indubitavelmente, de elemento facilitador para o encaminhamento do processo de articulação 
da economia do norte do Paraná à economia paulista, que marchava rumo à industrialização.

Por último, é importante frisar que a colonização do norte paranaense também contribuiu diretamente para a industrialização, no período pós-Segunda Guerra, como se pode observar na seguinte passagem:

Além de melhorar as condições para absorção de mão de obra, o rápido crescimento econômico do Paraná também contribuiu diretamente para o financiamento da industrialização de São Paulo. Isto ocorreu devido a alta taxação sobre os lucros da exportação do café no pós-guerra (através de uma supervalorização das taxas de câmbio). Esta renda foi posta à disposição, a taxas de câmbio subsidiadas, da importação de bens de capital para o setor industrial. (Graham e Holanda, 1984, p. 72)

\section{A colonização oficial}

Situação semelhante, pelo menos no que diz respeito à intensidade e à velocidade do processo, não poderia ter ocorrido nas regiões para onde se dirigiram os programas oficiais de colonização, embora seja possível inferir que o exemplo da colonização do norte do Paraná tornou-se um modelo a ser perseguido, numa vertente oficial, na colonização de outras áreas do território brasileiro.

A colonização oficial, como já foi afirmado anteriormente, passou a se destinar ao despertar de regiões consideradas adormecidas, que não haviam sido tocadas pelo avanço de frentes pioneiras e que também não eram consideradas interessantes para a inversão privada. Nesse caso, também, parece que se reproduziu a tônica presente em todas as outras manifestações econômicas do período. Apesar da forte intervenção econômica, o Estado brasileiro e o governo Vargas não preconizavam a estatização da economia. Agiam direta ou indiretamente onde os investimentos privados fossem insuficientes ou desinteressantes do ponto de vista de sua rentabilidade. Esse é o caso do processo que se consolidou na colonização do Oeste brasileiro, principalmente naquilo que ficou conhecido como Marcha para o Oeste.

Cumprindo basicamente o que se esperava dele nesse momento, que interferisse diretamente nas regiões e atividades econômicas que não 
apresentavam um impulso próprio no sentido da modernização, o Estado passou a substituir a ação privada e encaminhar o processo de conquista do interior brasileiro, nas regiões de Mato Grosso e Goiás, num processo colonizador que se basearia, entre outros elementos, no estabelecimento de pequenas propriedades de caráter familiar.

Esse papel reservado ao Estado como elemento dinamizador do interior brasileiro fica evidenciado na afirmação expressa em um artigo do professor João Villas-Boas, publicado na Revista Ciência Política ${ }^{5}$,

que representa, porém todo esse esforço progressista, limitado a tão minguados recursos financeiros, diante da vastidão do Estado e das distâncias consideráveis que medeiam entre os agrupamentos de população reduzida. Como a grande maioria dos Estados brasileiros, Mato-Grosso não pode atender às necessidades dos seus habitantes, nem promover o próprio desenvolvimento com a exploração das suas fabulosas riquezas naturais, utilizando-se apenas dos seus exíguos recursos orçamentários. Só a União poderá fazê-lo. E é o que já está fazendo, desde o momento em que o Sr. Presidente da República, numa visão superior dos mais vitais interesses do Brasil, traçou o programa de realizações práticas, que sintetizou na fórmula - "Marcha para o Oeste". (Villas-Boas, 1941, p. 26)

Como veremos, esse processo não apresentou os mesmos resultados da atividade colonizadora empreendida no norte do Paraná, pois a incorporação da região não conheceu a mesma velocidade e não alcançou os objetivos que, segundo o referido autor, haviam sido anunciados por Vargas:

5 Nessa época, as ideias de intelectuais ligados ao governo eram divulgadas, entre outros meios, por duas revistas editadas pelo Departamento de Imprensa e Propaganda (DIP): Cultura Política e Ciência Política. Essas revistas procuravam ser um fórum de debates acerca dos problemas nacionais. A Cultura Política era uma revista destinada a um público mais restrito e abrigava os intelectuais de maior porte que apoiavam o governo. Funcionava como um instrumento de articulação e difusão política em consonância com os objetivos do Estado Novo. A revista Ciência Política apresentava características semelhantes, possuía, entretanto, um caráter mais amplo, procurando atingir um público mais popular e uma intelectualidade "média". Apesar de seu nome, não tinha pretensões científicas e, pelo fato de seus artigos serem, na maior parte das vezes, transcrição de textos destinados a palestras, apresentava um caráter mais pragmático. 
É necessário à riqueza pública que o nível de prosperidade da população rural aumente para absorver a crescente produção industrial; é imprescindível elevar a capacidade aquisitiva de todos os brasileiros, o que só pode ser feito aumentando o rendimento do trabalho agrícola. Com esse intuito é que se empenha o Governo Nacional em fixar no campo os brasileiros animosos, reunindo-os em núcleos de colonização. (Villas-Boas, 1941, p. 28)

É evidente, contudo, que havia o interesse em incorporar a região Centro-Oeste à economia nacional e também que essa incorporação ocorresse principalmente pelo desenvolvimento de atividades agrícolas, baseadas em pequenas propriedades, cuja produção se dirigisse ao mercado, possibilitando, assim, que o pequeno proprietário passasse a ser consumidor de mercadorias industriais.

A necessidade de incorporação da região Centro-Oeste vinculou-se a uma série de avaliações presentes, no momento em questão, como um verdadeiro caso de segurança nacional. O Oeste brasileiro, principalmente Mato Grosso, era considerado uma região em iminente perigo de desmembramento do território nacional. Encontrava-se bastante presente, ainda, a memória da ocupação militar efetuada pelo Paraguai na segunda metade da década de 1860 . Ocupação essa que, segundo as avaliações do Dr.Villas-Boas, ocorreu não apenas por causa da segregação da região ao restante do país, mas também por seu despovoamento e pelas longas distâncias.

Tal situação teria sido amenizada pela ação posterior do governo imperial em fortificar a região; mas, apesar da aparente segurança da região, possibilitada pela presença militar, a situação econômica do norte mato-grossense permaneceu em estado de letargia: "Toda a região do Norte e do Centro do Estado definha". Tal situação contrastava com a pujança do Sul do Estado, que se beneficiou de seu contato econômico com São Paulo, durante as duas primeiras décadas do século XX: "Em contraposição o Sul entra numa fase de franca prosperidade. O intercâmbio com o Estado de São Paulo, facilitado pela Noroeste, atrai para ali uma população heterogênea de comerciantes, agricultores, artesões e aventureiros de toda a casta" (Villas-Boas, 1941, p. 23).

Segundo o mesmo autor, o surto desenvolvimentista no sul de Mato Grosso havia possibilitado, inclusive, um aumento da segurança na fronteira paraguaia, à custa, no entanto, de um maior descuido com a segu- 
rança na fronteira boliviana ${ }^{6}$. Esse breve surto econômico e povoador do Sul, todavia, refluiu no fim da Primeira Grande Guerra, fazendo com que todo o Estado entrasse novamente "no ritmo monótono da sua vida regular" (Villas-Boas, 1941, p. 24). Assim, para o referido autor, a defesa militar não seria suficiente para assegurar a presença efetiva do Estado brasileiro naquela parte do território nacional; seria necessário, pois, cuidar de sua defesa econômica, como única forma de garantir a real incorporação da região ao território nacional.

Ainda segundo o autor, isso só começara a ocorrer com a ascensão deVargas, que teria alcançado o mérito de superar os "golpes profundos de retardamento, em consequência das lutas partidárias, [...] [que] perturbavam o comércio, sacrificavam indústrias, arrasavam propriedades e despovoavam cidades" (Villas-Boas, 1941, p. 24). A ação do governo teria começado com um plano de transportes para a região e teria sido coroada, logo após a chegada do Estado Novo, com o estabelecimento de um importante plano povoador e colonizador baseado em pequenas propriedades (Villas-Boas, 1941, p. 29).

Percebe-se, por meio da avaliação acima resumida, que a colonização oficial no Oeste brasileiro inscrevia-se numa preocupação relativa à segurança nacional e à possibilidade de enfrentamento dos riscos de desmembramento dessa região do território brasileiro. Tais riscos, contudo, só seriam verdadeiramente solucionados se a referida região se integrasse de forma mais efetiva à atividade econômica nacional. A colonização baseada na pequena propriedade seria o fator que asseguraria a manutenção dessa parte do território, superando os custos e a ineficiência de uma defesa apenas militar. Infere-se, ainda, que a colonização não teria apenas o efeito de assegurar a manutenção de parte significativa, de aproximadamente um quinto do território brasileiro, mas seria elemento fundamental para o desenvolvimento do mercado interno nacional e para a exploração de sua riqueza natural, o que serviria de alavanca para o desenvolvimento industrial, fim real de toda ação integradora da região.

A ocupação do Oeste, apesar de se basear em atividades primárias, representava, na visão de alguns contemporâneos, um efetivo programa de fomento industrial. Nesse sentido, as afirmações apresentadas pelo

6 É interessante observar que a região fronteiriça com a Bolívia havia sido o local de exílio de uma parte significativa de combatentes da antiga Coluna Miguel Costa-Prestes. 
Dr. Djacir Menezes, membro do Conselho Nacional do Trabalho, em conferência denominada "O nacionalismo econômico no pensamento do presidente Vargas", realizada no Instituto Nacional de Ciência Política e transcrita na Revista Ciência Política, assumem grande importância instrumental.

$\mathrm{O}$ autor inicia o artigo criticando o liberalismo como doutrina elaborada pelos países centrais, para justificar a sua expansão imperialista, e como elemento de sustentação de uma democracia fictícia e formal, que havia se instalado no Brasil, no período anterior a 1930. Em seguida, defende o regime instaurado no pós-1930, principalmente com a instalação do Estado Novo, como uma democracia realista e funcional.

Seguindo esse percurso, o autor afirma que o regime e o seu chefe se caracterizavam por expressar um verdadeiro nacionalismo, cuja meta era superar a ação da "finança internacional" que impedia o alcance de "soluções dos problemas sociais que, por sua vez, só podem ter soluções nacionais condicionadas às particularidades geográficas, étnicas, históricas econômicas de cada povo" (Menezes, 1941, p. 63). Segundo o autor, a única solução possível encontrava-se "na defesa autárquica das nações, consultando, não os desígnios desumanos da finança internacional, mas os interesses legitimamente brasileiros" (Menezes, 1941, p. 64).

Dessa maneira, segundo o mesmo autor, o presidente e o novo regime conseguiram dar dois encaminhamentos necessários ao desenvolvimento brasileiro: a neutralização do problema da formação de núcleos homogêneos de imigrantes estrangeiros, que só chegaram a apresentar algum risco de fragmentação do território nacional devido à "imprevidência política dos governos da primeira República, distraídos com os sucessos eleitorais" (Menezes, 1941, p. 65); e a industrialização brasileira, simbolizada pelo programa de construção da grande siderúrgica. Essas duas atitudes haviam possibilitado a emergência do imperialismo brasileiro, que, na visão do autor, citando Vargas, "era pacífico: visava à conquista do próprio país, para dilatar suas fronteiras econômicas até as lindes de suas fronteiras políticas" (Menezes, 1941, p. 65). A decisiva opção pela conquista interna, ao permitir o aproveitamento de nossas riquezas naturais, representaria a possibilidade de desenvolvimento industrial: 
Acelera-se a conquista de nossas próprias riquezas naturais. As fronteiras econômicas se dilatam dentro do território a fim de coincidir com suas fronteiras políticas. No estabelecimento da coincidência dessas duas fronteiras está o mais luminoso programa de desenvolvimento industrial, livrando assim nossa economia de influências estranhas, dotando o Estado dos meios necessários para exploração e aproveitamento os nossos recursos naturais. (Menezes, 1941, p. 66)

Finalmente, o autor defende a industrialização como fator de desenvolvimento nacional ao criticar uma pretensa vocação agrícola brasileira, afirmando que tal visão se prende a teorias estranhas à realidade brasileira, como, por exemplo, o liberalismo, que se comportam como expressões de interesses externos, dos países centrais.

O velho chavão, que o acacianismo nacional repercutiu para nos convencer de que o "Brasil é um país essencialmente agrícola", foi forjado pelas nações industrializadas, que estavam interessadas no nosso agrarismo eterno. Elas exportaram para nós seus artigos maquinofaturados e levaram nossa matéria prima, beneficiando-se, ainda por cima, com o mecanismo parasitário de uma política de padrão ouro desangradora da nossa economia. Ainda nos escravizaram habilmente a teorias que exprimem interesses alheios e não os nossos. A título de ciência, se impuzeram doutrinas contrárias aos interesses nacionais, realejados nas escolas superiores, onde formaram elites afeitas às sutilezas da especulação juriforme, mas alheias, frequentemente, à gravidade dos problemas econômicos, encarados com a facilidade literária da oratória parlamentar. (Menezes, 1941, p. 66)

A avaliação acima se mostra extremamente interessante, pois expressa que o processo de conquista do interior brasileiro, consubstanciado no programa Marcha para o Oeste, mesmo que fundamentado em atividades ligadas ao setor primário da economia, seria fundamental para o desenvolvimento industrial do país.

O imperialismo interno brasileiro estaria contribuindo para a emergência de um novo padrão de acumulação, que necessitava de uma ação estatal que interviesse na economia, ultrapassando o livre jogo das forças de mercado. Ou seja, a industrialização deveria ser estimulada de maneira eficaz pelo Estado. Dentre esses estímulos estava a conquista do Oeste por elementos majoritariamente brasileiros, para que não se re- 
petissem os riscos à soberania nacional que chegaram a ser aventados pelos imigrantes que haviam se estabelecido em núcleos homogêneos ${ }^{7}$.

Assim, segurança nacional, preservação do território e mercado para o desenvolvimento industrial do país eram aspectos que se encontravam correlacionados na expectativa de colonização do interior brasileiro. A percepção de que a integração e a consolidação da unidade nacional estavam intimamente associadas à industrialização, que se concentrava no Centro-Sul, especialmente, São Paulo, apareceu de forma clara nas interpretações de Castelo Branco, escritor e jornalista piauiense, difundidas nas páginas da Revista Cultura Política, da qual ele era um assíduo colaborador:

As principais metrópoles do país transformaram-se em vivos focos de irradiação, não só econômica como cultural. O Rio de Janeiro e São Paulo, sobretudo, erguem parques industriais de $1^{\underline{a}}$ grandeza, exercendo sobre o resto do país, dia a dia mais, esta dualidade de forças peculiar aos corpos em movimento: uma centrípeta, alargando-a mais e mais; outra centrifuga prendendo os demais centros em seus elos econômicos e sociais. Com seu desenvolvimento e a especialização das economias regionais, integram-se todas elas, cada vez mais fortemente, num poderoso organismo homogêneo, revitalizado pela circulação interna do pensamento e da riqueza. O estímulo deste intercâmbio [...] é assim obra do mais puro nacionalismo. (Castelo Branco, 1941, p. 90)

Podemos observar que o autor acima trabalha com razoável clareza em relação ao processo de integração do mercado interno. Para ele, essa integração era comandada pelo processo de industrialização que se encontrava concentrado nas principais metrópoles brasileiras, particularmente São Paulo, chegando inclusive a abordar a constituição de economias regionais especializadas integradas pelo centro, num organismo homogêneo. Esse seria o caso do Oeste brasileiro, que, povoado e integrado economicamente à base da pequena propriedade, se especializaria na produção de gêneros destinados aos centros urbanos e no consumo de mercadorias industriais.

Essa é também uma das interpretações presentes na historiografia. Lenharo, ao analisar o processo de Marcha para o Oeste como impor-

7 Exemplo disso eram as notícias sobre um projeto nazista de se criar uma Alemanha Antártica a partir das colônias de imigrantes alemães do Sul do Brasil. 
tante elemento de constituição da ideologia estado-novista, chega a afirmar que

a mudança da paisagem social da Amazônia, de Mato Grosso e de Goiás se amarra na ideia de ampliação do mercado interno de consumo para absorver a crescente produção industrial. Isto através da irradiação da pequena propriedade, tomada como o meio de se aumentar o rendimento do trabalho agrícola. (Lenharo, 1986a, p. 97)

Existem, ainda, interpretações que trabalham com a ideia de que o processo de ocupação do Oeste, por meio de um projeto colonizador baseado na pequena propriedade, estaria voltado, no longo prazo, a homogeneizar as condições de desenvolvimento do país, única forma de se garantir a manutenção de sua integridade territorial. Isso é o que considera Diniz Filho, ao analisar a política territorial de Vargas como expressão de uma ideologia geográfica que procurava identificar a construção da nacionalidade brasileira como resultado da construção de seu território, observando que a manutenção da integridade do território nacional era o objetivo máximo do processo de conquista territorial, empreendida pela Marcha para o Oeste. Essa manutenção da integridade territorial só seria alcançada, na visão de Vargas e dos ideólogos do regime, se os desequilíbrios econômicos regionais fossem atenuados. Por isso, as colônias agrícolas previstas seriam polos irradiadores de desenvolvimento regional:

A integração proposta pelo presidente consiste, pois, numa modernização da estrutura produtiva em toda a extensão territorial do país, objetivo este que exigiria a montagem de um setor de bens de produção (para difundir o progresso técnico por todos os setores produtivos e por todas as regiões do país), e um desenvolvimento da atividade mineradora, capaz de mobilizar os recursos ainda inaproveitados do território nacional para a implantação das indústrias de base. (Diniz Filho, 1993, p. 91)

Esse mesmo autor afirma, no entanto, que, para tal, seria necessária uma etapa anterior, em que a indústria nacional tivesse assegurado a sua dinâmica própria, a partir do favorecimento daquelas indústrias que, no momento em questão, encontravam-se espacialmente concentradas. 
Mas, antes que o progresso técnico se irradiasse por todo o território, o Brasil continuaria marcado por uma profunda heterogeneidade, expressa na existência do que Vargas denominou de "regiões geo-economicas". Até o dia em que o Brasil pudesse finalmente constituir "um corpo econômico homogêneo". O Estado deveria ajustar suas prioridades segundo as características de cada região, tal como segue: "no centro, a carência de transportes, $\mathrm{o}$ aproveitamento das vias fluviais, os meios de acesso às riquezas do sub-solo, serão as prioridades dominantes, conjugadas com os esforços para acelerar o povoamento. No Norte, o reagrupamento das populações, o combate às endemias, a valorização e industrialização dos produtos nativos, com a melhoria das comunicações e transportes, constituirão núcleo do esforço geral da União, dos Estados e Municipalidades. No Nordeste, onde já são vultosas inversões de dinheiro público em obras de fixação da população, é preciso prosseguir nos rumos traçados - açudagem, irrigação, estradas e policultura. No sul, onde se acham localizadas as maiores lavouras e cerca de $80 \%$ das indústrias, persistiremos na obra encetada, de apoio aos empreendimentos produtivos". (Diniz Filho, 1993, p. 91)

Nesse sentido, o processo de integração econômica do Oeste serviria como base de apoio para o desenvolvimento industrial paulista, mesmo que se cogitasse, no futuro, uma possível desconcentração dessa atividade. Tal consideração pode ser pertinente, se atentarmos que ela reflete uma postura bastante presente na concepção de mundo e de sociedade, influenciada, entre outras tendências, pelo positivismo que impregnava o pensamento de Vargas, ou seja, a ideia de que todo processo deve seguir etapas bem definidas.

As etapas a serem seguidas, bem como a defesa da industrialização como sinônimo de progresso e modernização, são elementos presentes e importantes no pensamento e na prática positivista. Assim, antes de generalizar-se por todo o território brasileiro, a industrialização deveria ter uma base sólida a ser constituída pelo favorecimento do setor industrial que se apresentava no momento e que se concentrava em São Paulo. Não era, portanto, fortuita a afirmação de Vargas a respeito da existência de duas economias: uma, que seria o "sujeito" (caracterizada por São Paulo), e outra, que seria o "objeto” (caracterizada pelo Oeste) do imperialismo brasileiro.

Podemos, dessa forma, compreender que a proposta de colonização do Oeste, no momento que nos ocupa, voltava-se, sim, a favorecer a 
acumulação urbano-industrial, que se centralizava e se concentrava em São Paulo. Só posteriormente, a partir dessa concentração inicial, é que se poderia pensar numa desconcentração industrial e na homogeneização do desenvolvimento. No momento em questão, portanto, os graus de desenvolvimento das diferentes regiões deveriam ser desiguais para que a industrialização tivesse curso.

Outra interpretação interessante é a que sustenta a tese de que o processo de colonização por meio de pequenas propriedades, entre outros atributos, significaria uma estratégia cautelosa de enfrentamento ao latifúndio, por tudo o que ele representava em termos de atraso, autossuficiência, poder local e ênfase na atividade exportadora. Na medida em que um enfrentamento direto aos interesses representados pelo latifúndio poderia ter um resultado politicamente catastrófico, o governo preferiu, aparentemente, estabelecer uma estratégia de conciliação e não enfrentá-los diretamente, mas enfraquecê-los, paulatinamente, pelo crescimento da produção familiar destinada ao mercado interno. $\mathrm{O}$ enfrentamento ao latifúndio se daria pela consolidação de uma classe de pequenos proprietários, numericamente significativa, que poderia contrabalançar a influência política e econômica dos grandes proprietários de terra:

Delineia-se, assim, a estratégia de colonização: armar um cerco ao latifúndio, de fôlego longo. Apoiar a pequena propriedade de modo a que ela, lentamente, corroesse a velha ordem latifundiária, e, aos poucos, instaurasse a nova realidade agrícola que o desenvolvimento industrial do país exigia. (Lenharo, 1986a, p. 97)

Essa visão estava presente em pensadores do período, dentre os quais OliveiraVianna, para quem a pequena propriedade era fundamental para a efetiva constituição da sociedade brasileira. Segundo esse autor, enquanto a grande propriedade continuasse hegemônica, o Brasil estaria sem "quadros sociais completos; sem classe média; sem classe industrial; sem classe comercial" (Paiva, 2004, p. 35).

Essa perspectiva é bastante generosa e tentadora, pois efetivamente pode sugerir a hipótese de que o processo de colonização oficial do Oeste teria como referência dois exemplos históricos: o avanço das fronteiras ocorrido nos Estados Unidos, no século XIX, e o processo 
brasileiro que se desenvolvia simultaneamente, a colonização do norte do Paraná.

A relação com o ocorrido nos Estados Unidos, no século XIX, é bastante interessante e realmente apresenta razoáveis similitudes com o que se pretendia alcançar no Brasil, ressalvando, evidentemente, que lá o avanço das fronteiras econômicas rumo ao oeste serviu, de acordo com a tradicional tese de Turner (Velho, 2009, p. 131), como fator legitimador da democracia liberal e aqui, ao contrário, era utilizado para justificar e legitimar o regime autoritário ${ }^{8}$.

$\mathrm{O}$ avanço norte-americano ao oeste, sustentado na pequena propriedade de caráter familiar, permitiu, ao mesmo tempo, a construção de um mercado interno para as indústrias concentradas no nordeste daquele país e a realização de uma espécie de parceria entre as duas regiões que isolou econômica mas principalmente politicamente o sul latifundiário (Moore, 1983, p. 116-119). É verdade que tal situação levou ao risco de secessão, mas esta pôde ser evitada com a superioridade material do norte e, levou, no final das contas, ao estabelecimento de uma hegemonia industrialista sobre a economia e a política norte-americanas. No caso brasileiro, ainda, o controle de todo o processo por um Estado interventor tenderia a afastar de forma mais efetiva qualquer risco posterior de secessão.

A experiência coetânea que se desenvolvia no norte do Paraná também pôde demonstrar, pelo explosivo crescimento populacional da região, que o pequeno proprietário poderia se transformar em um agente numericamente importante e que tal dimensão acarretaria uma ampliação de sua participação política num futuro razoavelmente próximo.

Ao mesmo tempo, a não interferência direta, num primeiro momento, ao poder do latifúndio se revelava instrumentalmente importante para o processo de povoamento do Oeste, de acordo com as características que se pretendia imprimir a ele, ou seja, um povoamento que articulasse tal região não só ao mercado brasileiro, mas também o fizesse com a garantia de seu controle nacional.

Vargas por várias vezes se referiu ao esforço do governo em garantir a fixação da população no Nordeste, no entanto, esse esforço limitava-se, apenas, à realização de obras que procuravam amenizar as causas naturais

8 Ver também Ricardo, 1970; e Lenharo, 1986 b. 
que geravam fatores de expulsão da população nordestina, tais como as obras de combate à estiagem ${ }^{9}$. As questões relativas ao combate às causas sociais de expulsão populacional mereceram prudência muito maior. Nesse sentido, as críticas em relação aos latifúndios, como fator de geração de excedentes populacionais e de sua expulsão, não encontraram a mesma ênfase nos discursos presidenciais.

Pode-se argumentar que uma intervenção na estrutura fundiária era algo que fugia às possibilidades históricas do período, pois corresponderia a uma espécie de suicídio político, na medida em que, com tal atitude, o governo desencadearia fortes pressões dos grupos dominantes do Nordeste, num momento em que precisava constituir bases de apoio. Essa questão, contudo, explicita o fato de que as políticas relativas aos deslocamentos populacionais e à colonização, que foram sendo elaboradas no período que nos ocupa, apresentavam um caráter refinado no que se refere à ideia de política como administração de conflitos e interesses, com o propósito de alcançar objetivos definidos.

Assim, ao não intervir na estrutura tradicional da economia e sociedade nordestinas, o governo, ao mesmo tempo em que não gerou descontentamentos entre os seus grupos dominantes, permitiu que o Nordeste cumprisse a função de fornecedor de uma abundante força de trabalho que poderia atender às novas exigências migratórias.

A manutenção da tradicional estrutura da propriedade nordestina pode ser considerada uma importante face da política migratória do período e nos ajuda a compreender como essa política foi sendo elaborada não apenas no sentido de dirigir os movimentos populacionais para determinadas regiões, mas também de como "produzir" esses mesmos movimentos populacionais.

Tratava-se, ainda, de um "tipo" de deslocamento populacional que se vinculava aos objetivos de ocupação do interior com segurança nacional. Se a ocupação do Oeste permitiria a sua ligação, via mercado, com as regiões mais industrializadas, situadas ao Sul, principalmente São Paulo, o

Mesmo esses esforços eram considerados insuficientes por autoridades locais como fator de fixação populacional. Paiva (2004, p. 131) apresenta, em seu trabalho, uma série de telegramas enviados por prefeitos nordestinos reclamando da demora em se concluir obras de combate à seca. Nesses telegramas, os prefeitos são enfáticos em afirmar que a não realização de tais obras acarretava como consequência a fuga de população e a formação de um enorme contingente de retirantes. 
seu povoamento com contingentes populacionais nacionais, vindos do Nordeste, garantiria a sua ocupação com um elemento humano menos contaminado por influências externas e, portanto, mais expressivo de uma identidade e de uma cultura efetivamente nacionais. A caracterização do nordestino, como um "tipo" humano que preservou mais diretamente as características nacionais, é encontrada nesta passagem de Castelo Branco:

Enquanto o sul, com a imigração intensiva, enveredava por estradas novas em sua civilização [...] o norte se conservava fiel ao bloco original [...]; no Setentrião todos os elementos culturais gravitaram em torno de Salvador e Recife cuja influência se irradiava avassaladora, favorecendo a unidade espiritual, ao contrário do sul. [...] Isolado do contato externo, exceção feita da influência espiritual francesa, recebida mais ou menos indiretamente, o nortista elaborou uma mentalidade muito mais nativista e una. Deste modo, segregado de qualquer corrente migratória ponderável, isento de fatores estranhos que perturbassem a elaboração de sua sólida unidade e conservando, na formação racial, unicamente os elementos primitivos, o nortista é, em geral, um brasileiro de várias gerações, por todos os costados, radicalmente nativista [...]. E graças a isto, cabe sem dúvida, a ele, ou mais precisamente, ao nordestino, o grande papel de guardião da unidade brasileira. [...] Animados desta extraordinária força centrífuga, os nordestinos desempenham, modernamente, o papel que os bandeirantes desempenharam no passado, em relação à unidade nacional, espalhados pelo Brasil como uma teia defensora contra a desagregação, que a diferença de progresso e de migração, os erros políticos e a trama oculta dos imperialismos já teriam, sem ela, realizado. (Castelo Branco, 1941, p. 28-30)

Assim, a colonização por meio da pequena propriedade no Oeste brasileiro seria fator de união das características do Sul e do Nordeste, do mesmo modo que a sua realização seria resultado dessa união. Do Sul, identificado com a modernização e com a industrialização, viriam os influxos econômicos que permitiriam a incorporação dessa região ao mercado brasileiro, como produtora e consumidora de mercadorias. O Sul, entretanto, não dispunha de excedentes populacionais significativos, uma vez que parte de sua população já estava sendo atraída pelo crescimento industrial dos centros urbanos e pela frente pioneira que estava se abrindo no norte do Paraná, de tal sorte que a sua própria agricultura já reclamava da ausência de braços que eram buscados, inclusive, no próprio Nordeste ou em Minas Gerais. 
É do Nordeste, portanto, que deveriam vir os recursos humanos necessários à tarefa de povoamento e colonização. Elementos humanos que, além de excedentes em seus lugares de origem, apresentariam a vantagem de não se encontrar contaminados por culturas e ideologias estranhas nem de representar interesses de firmas e governos estrangeiros e que não gerariam "quistos étnicos" em uma parte do território potencialmente ameaçada de desmembramento. Mais ainda, era um contingente populacional que poderia ser convertido à economia de mercado e a relações sociais mais próximas das exigidas pelo avanço capitalista, bastando para tal que nele fossem incutidos, como afirmou Vargas, "hábitos de atividade e economia" (Vargas, 1943b, p. 28). Daí a necessidade de agrupá-los, controlá-los e discipliná-los em colônias agrícolas regidas por forte hierarquia e controle.

A colonização do Oeste responderia, dessa forma, aos imperativos de integração do mercado sobre a égide do novo padrão de acumulação e permitiria certa garantia de nacionalização do território. Tal processo permite vislumbrar que a integridade do território, ao mesmo tempo em que seria garantida pelo desenvolvimento do mercado e da industrialização, seria, reversamente, um fator de impulsão ao desenvolvimento industrial, na medida em que representaria a construção de um novo mercado para a produção brasileira.

Paralelamente à formulação do programa de integração, colonização e povoamento do Oeste, que ficaria conhecido como Marcha para o Oeste, já se desenvolviam, em São Paulo, experiências oficiais de colonização em regiões não tocadas pelas frentes pioneiras do café, consideradas adormecidas e denominadas como "sertão" ou "Amazônia Paulista”. São os casos do NCBA (Núcleo Colonial Barão de Antonina), localizado em Itaporanga, e das áreas de colonização do Vale do Ribeira, localizados, respectivamente, nas regiões sudoeste e sul do estado.

Nesses casos, principalmente no caso do NCBA, as autoridades afirmavam que se estava construindo uma nova experiência colonizadora: "O NCBA seria o ponto inicial de uma nova política de colonização para o estado de São Paulo"10. Segundo essas mesmas autoridades, seria o NCBA "uma mostra de uma política inteligente e persuasiva de

10 A colonização oficial em São Paulo e o Núcleo Colonial Barão de Antonina. Boletim do SIC. São Paulo, n. 2, p. 13, outubro de 1940. 
assimilação"11 e uma Colmeia de trabalho e de nacionalização em pleno sertão paulista $^{12}$. Isso permite observar que nesse núcleo já se imprimiam características da política colonizadora que se objetivaria praticar no Oeste: a ênfase na produção em pequenas propriedades voltadas ao mercado e a nacionalização dessa produção pela priorização do elemento nacional e assimilação do estrangeiro. Em relação a essa situação, ao comentar a posição de técnicos, que, pautados na experiência concreta do NCBA, defendiam a ampliação da instalação de núcleos coloniais, Paiva observou:

O Núcleo colonial emergia como a concretização de uma ação mais efetiva e moderna do Estado no fomento à pequena produção. $\mathrm{O}$ Estado criava, nesses núcleos, uma organização mais complexa. [...] Neste sentido, o Núcleo Colonial, na perspectiva dos técnicos, representava uma ação modelo, onde o Estado assumiria, de forma efetiva, parcela importante da responsabilidade no fomento à pequena produção. (Paiva, 2002, p. 79-80)

Nesse sentido, é possível inferir que, na virada das décadas de 1930 e 1940, a experiência colonizadora do NCBA permitiu que se formasse, do ponto de vista técnico, uma evidência concreta de que a estratégia oficial de colonização de regiões consideradas adormecidas e não atraentes à inversão privadas poderia ser estendida ao Oeste, como interessante à realização de um novo tipo de colonização adequado aos processos de desenvolvimento em curso no período. Isso ganha mais destaque, se observarmos que a experiência paulista do NCBA começava a demonstrar que era possível produzir e comercializar um importante insumo agrícola, como o algodão, a preços inferiores à média do mercado, como pode ser observado no quadro abaixo:

11 A colonização oficial em São Paulo e o Núcleo Colonial Barão de Antonina. Boletim do SIC. São Paulo, n. 2, p. 16, out. 1940.

12 Nome de um filme a respeito do NCBA, produzido pelo DPDC (Departamento de Produção e Difusão Cultural), antecessor do DIP (Departamento de Imprensa e Propaganda), em 1938. 


\begin{tabular}{|c|c|c|c|}
\hline \multicolumn{4}{|c|}{ Quadro 1 - Preço médio do algodão - Bruto por arroba em Cr\$ } \\
\hline ANO & $\begin{array}{l}\text { PRECCO MÉDIO POR } \\
\text { ARROBA - NCBA* }\end{array}$ & $\begin{array}{l}\text { PREÇO MÉDIO POR } \\
\text { ARROBA - ESTADO } \\
\text { DE SÃO PAULO } \star \star\end{array}$ & $\begin{array}{l}\text { PROPORCCÃO DO PREÇO MÉDIO POR } \\
\text { ARROBA DO NCBA EM RELAÇÃO AO } \\
\text { PREÇO MÉDIO POR ARROBA DO ESTADO } \\
\text { DE SÃo PAULO }\end{array}$ \\
\hline 1942 & 17,37 & 19,2 & $90,46 \%$ \\
\hline 1943 & 22,00 & 25,7 & $85,60 \%$ \\
\hline 1944 & 20,00 & 27,5 & $72,72 \%$ \\
\hline 1945 & 19,25 & 27,8 & $69,24 \%$ \\
\hline \multicolumn{4}{|c|}{$\begin{array}{l}\text { Fonte: } \\
\star \text { Relatórios da agricultura do NCBA, 1942, 1943, 1945; Hi: 4184/04 de janeiro de 1943; 4272a/03 } \\
\text { de dezembro de 1943; 5204a/20 de novembro de } 1945 . \\
\star \star \text { Albuquerque, 1982, p. } 173 \text {. }\end{array}$} \\
\hline
\end{tabular}

A influência da experiência do NCBA na consolidação da política de colonização do Oeste pode ser sugerida pela participação do Sr. Henrique Doria de Vasconcelos na composição do Conselho de Imigração e Colonização (CIC), após 1938. Ele havia sido o chefe do Departamento de Terras e Colonização (DTC) paulista e o responsável pela efetiva instalação do NCBA após 1931. Esse fato talvez não seja apenas uma coincidência, já que o NCBA era considerado um laboratório de novas experiências colonizadoras.

\section{A colonização do Oeste: nacionalização e apoio à industrialização}

Com a criação das Colônias Agrícolas Nacionais, as CANs, por meio do Decreto-Lei n. 3.059 de 14 de fevereiro de 1941, o governo explicitou a sua intenção de empreender a colonização do Oeste. A criação das CANs que se destinavam a ser a "espinha dorsal da Marcha para o Oeste" foi precedida por uma nova regulamentação dos núcleos coloniais, estabelecida no Decreto-Lei n. 2.009 de 9 de fevereiro de 1940, de tal sorte que esses dois instrumentos legais encontram-se relacionados ${ }^{13}$.

13 O decreto-lei de criação das CANs faz várias referências ao decreto-lei que dá nova organização aos núcleos coloniais, tais como em seu primeiro artigo, indicando as CANs como outra possibilidade de colonização, e no artigo 16, que trata sobre os lotes urbanos e rurais. Os artigos que tratam das condições para a criação das colônias, das áreas dos lotes, das benfeitorias, dos auxílios aos colonos, bem como 
O Decreto-Lei n. 2.009 reiterava princípios estabelecidos em instrumentos legais, acerca da colonização e da assimilação dos estrangeiros, instituídos em 1938. Além de reforçar o direito de inspeção pelo governo federal de qualquer núcleo colonial, seja ele privado ou oficial, indicava, também, as condições para a localização dos núcleos, para a sua organização produtiva e administrativa e, ainda, para a aquisição dos lotes e para a concessão de favores aos colonos. Em relação ao último aspecto, reafirma o Decreto n. 3.010 de 20 de agosto de 1938, ao instituir que "serão cassados os favores estabelecidos neste decreto aos colonos, que nos núcleos coloniais transgredirem ou deixarem de cumprir" as suas disposições.

O Decreto n. 3.010 regulamentava o Decreto-Lei n. 406, de 4 de maio de 1938, que versava sobre a entrada de estrangeiros no Brasil. O Decreto n. 3.010 apresentava um título voltado à questão da concentração dos estrangeiros e de sua assimilação. Nessa parte, o texto dispunha, no artigo 165, que nenhum núcleo colonial poderia ser constituído por estrangeiros de uma só nacionalidade; que o governo federal, por meio da Divisão de Terras e Colonização (DTC), fiscalizaria os núcleos coloniais estaduais, municipais e até mesmo particulares; que essa fiscalização seria exercida com o objetivo de impedir a criação de núcleos coloniais com estrangeiros de uma só nacionalidade, de evitar que neles ocorresse a preponderância ou concentração de estrangeiros de uma nacionalidade e de evitar, ainda, que os colonos estrangeiros deixassem, nos primeiros quatro anos, a profissão com a qual foram admitidos no país. Previa, em seu artigo 166, que em qualquer núcleo colonial fosse mantido um mínimo de 30\% de brasileiros natos e um máximo de 25\% de estrangeiros de cada nacionalidade; que, na falta de brasileiros, o CIC poderia autorizar a fixação de imigrantes portugueses; que nenhum colono poderá tomar posse do lote sem apresentar prova de que está inscrito no Registro de Estrangeiros; que, para os colonos já localizados, será exigida a prova de registro perante a autoridade policial e que, para cômputo dessas percentagens, seriam considerados os maiores de 12 anos, de ambos os sexos. No artigo 169, que nenhum núcleo colonial, estabelecimento de comércio, indústria ou associação nele existente po-

dos fatores que poderiam levar à sua reclusão, reproduzem, de forma praticamente literal, os artigos do decreto-lei anterior. 
deria ter denominação em idioma estrangeiro. Por último, afirmava que, em caso de inobservância dos dispositivos legais, o CIC poderia tomar as providências administrativas que julgasse conveniente. Sobre essas providências poderia caber recurso, porém sem efeito suspensivo.

Nesse "emaranhado" de instrumentos legais, como decretos e decretos-lei, verifica-se que as CANs foram introduzidas como elementos necessários à conquista nacional do interior brasileiro, nos vários sentidos possíveis atribuídos a esse termo: por basear-se no elemento brasileiro; por procurar disciplinar o trabalho do migrante brasileiro; por controlar a presença e a atuação estrangeira e, consequentemente, por evitar a formação de colônias que ameaçassem a integridade territorial. Uma integridade territorial que só seria assegurada pela integração econômica da região e que só teria sentido, caso se voltasse também à expansão do mercado, que se tornaria cativo da produção nacional.

Para esse fim, a criação das CANs incorporava, indubitavelmente, aspectos dos instrumentos legais que forjavam uma política relativa aos problemas migratórios e das experiências colonizadoras coevas, privadas e oficiais. Das oficiais, incorporava a centralização e a hierarquização burocrática, o controle administrativo sobre os colonos, a produção em pequenas propriedades dirigidas ao abastecimento industrial e urbano e a preocupação com a nacionalização da iniciativa. Questões como as referidas, principalmente as três primeiras, em certa medida, encontravam-se presentes também nas iniciativas particulares. Mas, destas, principalmente da que ocorria no norte do Paraná, a criação das CANs incorporou a preocupação com a formação de um grande complexo colonizador voltado a transformar-se num espaço irradiador de desenvolvimento, preenchendo o chamado vazio demográfico.

Esse era o fator que diferenciava a proposta oficial de colonização do Oeste da experiência colonizadora privada: a colonização oficial voltava-se a regiões desinteressantes ao investimento privado. Ela não estava capturando um processo em curso, uma oportunidade de desenvolvimento oferecida pelo avanço do capital, deveria, ao contrário, ser o instrumento de impulsão do desenvolvimento capitalista na região de sua instalação:

[As CANs foram armadas como] "um rosário de colônias", pontos avançados de penetração, impulsionadores da "Marcha para o Oeste" e de 
conquista da Amazônia. Do modo como foram planejadas, as colônias funcionariam como cidades-indústrias lançadas no vazio. [...] A criação das colônias agrícolas nacionais constitui um momento de uma escalada da política colonizadora, que começou a ser pensada após a famosa proclamação da "Marcha para o Oeste". (Lenharo, 1986a, p. 125)

Daí o caráter estratégico de sua localização e a preocupação em introduzir os colonos em novas relações sociais. Dentre as CANs projetadas, pelo menos duas, a de Dourados, em Mato Grosso ${ }^{14}$, e a de Goiaz ${ }^{15}$, em Goiás, "teriam o mercado paulista em mira" (Lenharo, 1986a, p. 122). As outras, do Pará, Amazonas, Maranhão, Piauí e Paraná visavam mais diretamente incentivar o desenvolvimento local e regional, vinculando-se aos mercados mais próximos. Mesmo nessas CANs, no entanto, a preocupação com a nova ordem capitalista encontrava-se expressa, já que o artigo 5ำ, do Decreto-Lei n. 3.059 (de criação das CANs), dispunha o seguinte:

Fixada a região onde a colônia deverá ser fundada, será projetada a sua futura sede, escolhendo-se para isso a zona que oferecer melhores condições. [...] Parágrafo único: No projeto da sede serão observadas todas as regras urbanísticas, visando a criação de um futuro núcleo de civilização no interior do país.

Dessa maneira, é lícito inferir que, se os objetivos em relação às sedes das CANs eram transformá-las em postos avançados de civilização e modernização no interior do país, isso objetivaria, também, a transformação delas em centros consumidores de mercadorias industriais. Favorecendo o desenvolvimento do novo padrão de acumulação capitalista, nucleado naquele momento pela industrialização que estava se concentrando em São Paulo.

14 A CAN de Dourados, criada pelo Decreto-Lei n. 5.941 de 28 de outubro de 1943 , havia sido instalada, em realidade, no recém-criado território federal de Ponta-Porã. Tal território, criado juntamente com outros pelo Decreto-Lei n. 5.812 de 13 de setembro de 1943, tinha por objetivo garantir maior controle federal sobre as áreas de fronteira. Isso mostra a relação existente entre colonização e garantia da segurança e integridade territorial, uma vez que a CAN de Dourados não deveria ter uma área inferior a 300.000 hectares. Tal território, entretanto, teve existência efềmera, deixou de existir com a Constituição de 1946.

15 A CAN goiana foi criada pelo Decreto n. 6.882 de 19 de fevereiro de 1941, no município de Goiaz. Entretanto, tal CAN deu origem ao município de Ceres. 


\section{Referências bibliográficas}

A COLONIZAÇÃO oficial em São Paulo e o Núcleo Colonial Barão de Antonina. Boletim do SIC. São Paulo, n. 2, out. 1940.

ALBUQUERQUE, Rui H. P. L. de. Capital comercial, indústria têxtil e produção agrícola. São Paulo: HUCITEC/CNPq, 1982.

ALMEIDA, Ana Maria Chiarotti de. A morada do vale, sociabilidade e representações: um estudo sobre as famílias pioneiras do Heimtal. Londrina: UEL, 1997.

AUGUSTO, Maria Helena Oliva. Intervencionismo estatal e ideologia desenvolvimentista. São Paulo: Símbolo, 1977.

CAMARGO, Aspásia A. A questão agrária: crise de poder e reformas de base (19301964). In: FAUSTO, Bóris (org.). História geral da civilização brasileira. Rio de Janeiro: DIFEL, 1981, v. 3.

CASTELO BRANCO, R. P. A unidade brasileira e suas causas determinantes. Cultura Política. Rio de Janeiro, DIP, ano I, n. 2, abril de 1941.

CORSI, Francisco Luiz. Política econômica e nacionalismo no Estado Novo. In: SUZIGAN, Wilson e SZMRECSANYI, Tamás (orgs.). História econômica do Brasil contemporâneo. 2. ed. rev. São Paulo: EDUSP/HUCITEC/Imprensa Oficial, 2002.

DINIZ FILHO, Luís Lopes. Território e destino nacional: ideologias geográficas e políticas territoriais no Estado Novo (1937-1945). São Paulo: Universidade de São Paulo, 1993 (Dissertação de Mestrado em Geografia).

GRAHAM, Douglas H. Algumas considerações econômicas para a política migratória no meio brasileiro. In: GRAHAM, Douglas H. Migrações internas no Brasil. Rio de Janeiro: IPEA/INPES, 1971.

GRAHAM, Douglas H.; HOLANDA FILHO, Sérgio Buarque de. Migrações internas no Brasil, 1872-1970. São Paulo: Instituto de Pesquisas Econômicas, 1984.

JARRETA, Maria Helena. Contribuição para a análise de um espaço norte-paranaense: a área colonizada pela Companhia de Terras do Norte do Paraná. Anais do $4^{\circ}$ Congresso da AGB. São Paulo: Associação dos Geógrafos Brasileiros, julho de 1984.

LAHUERTA, Milton. Os intelectuais e os anos 20: moderno, modernista, modernização. In: COSTA, Wilma Peres da e LORENZO, Helena Carvalho de (orgs.). A década de 1920 e as origens do Brasil moderno. São Paulo: UNESP/FAPESP, 1997.

LENHARO, Alcir. A conquista do corpo geográfico do país. Campinas: UNICAMP, 1986a.

LENHARO, Alcir. Sacralização da política. Campinas: Papirus, $1986 \mathrm{~b}$.

MENEZES, Djacir. O nacionalismo político no pensamento do presidente Vargas. Revista Ciência Política. Rio de Janeiro, Instituto Nacional de Ciência Política/DIP, n. 5, 1941.

MARTINS, José de Souza. Frente pioneira: contribuição para uma caracterização sociológica. Estudos Históricos. Marília, Departamento de Educação, Faculdade de Filosofia Ciências e Letras de Marília, n. 10, 1971.

MONBEIG, Pierre. Pioneiros e fazendeiros de São Paulo. 2. ed. São Paulo: Pólis/HUCITEC, 1994. 
MOORE JR., Barrington. Origens sociais da ditadura e da democracia. São Paulo: Martins Fontes, 1983.

PAIVA, Odair da Cruz. Colonização e (des)povoamento. São Paulo: Pulsar, 2002.

PAIVA, Odair da Cruz. Caminhos cruzados: migração e construção do Brasil moderno (1930-1950). Bauru: EDUSC, 2004.

RICARDO, Cassiano. Marcha para o Oeste. 4. ed. Rio de Janeiro: José Olympio, 1970.

VAR GAS, Getúlio. Diretrizes da nova política do Brasil. Rio de Janeiro: José Olympio, s.d. (1943a).

VARGAS, Getúlio. Nova política do Brasil. Rio de Janeiro: José Olympio, s.d. (1943b).

VELHO, Otávio Guilherme. Capitalismo autoritário e campesinato. Rio de Janeiro: Biblioteca Virtual de Ciências Humanas do Centro Edelstein de Pesquisas Sociais, 2009. Disponível em <http://www.bvce.org/LivrosBrasileirosDetalhes.asp?IdRegistro=79>.

VILLAS-BOAS, João. O sertão e a política construtiva do presidente Getúlio Vargas. Revista Ciência Política. Rio de Janeiro, Instituto Nacional de Ciência Política/DIP, n. 5, 1941. 